\title{
ENGINEERS' AND BIOLOGISTS' ROLES DURING BIOMIMETIC DESIGN PROCESSES, TOWARDS A METHODOLOGICAL SYMBIOSIS
}

\author{
Graeff, Eliot; Maranzana, Nicolas; Aoussat, Améziane \\ École Nationale Supérieure d'Arts et Métiers (ENSAM)
}

\begin{abstract}
The strength of biomimetics comes from its ability to draw from life mechanisms and strategies to design innovative solutions. In spite of recent methodological progresses, more specifically on tools and processes, biomimetics' implementation still faces strong difficulties. Among other things, design teams have a hard time finding and selecting relevant biological strategies. Facing these challenges, we consider an alternative, yet well recognized, approach: the integration of profiles having a training in natural science within biomimetic design teams. As biologists aren't used to work in design teams, there is a need for a process actually guiding their practice in biomimetics and determining the way they will interact with the "traditional" design team. After studying the literature and asking for experts' opinion on the matter, we introduced a biomimetic design process considering this new profile as an integral part of biomimetic design teams. With the final goal of making biomimetics implementable, this proposed theoretical process is currently tested in both a student and an industrial project in order to optimize our methodological contribution with practical feedbacks.
\end{abstract}

Keywords: Bio-inspired design / biomimetics, Biologists, Design process, Collaborative design, Design Team

Contact:

Graeff, Eliot

École nationale supérieure d'arts et métiers (ENSAM)

LCPI

France

eliot.graeff@ensam.eu

Cite this article: Graeff, E., Maranzana, N., Aoussat, A. (2019) 'Engineers' and Biologists' Roles during Biomimetic Design Processes, Towards a Methodological Symbiosis', in Proceedings of the 22nd International Conference on Engineering Design (ICED19), Delft, The Netherlands, 5-8 August 2019. DOI:10.1017/dsi.2019.35 


\section{INTRODUCTION}

Biomimetics is defined as "the interdisciplinary cooperation of biology and technology or other fields of innovation with the goal of solving practical problems through the function analysis of biological systems, their abstraction into models and the transfer into and application of these models to the solution" (ISO/TC266, 2015). The innovative potential of this approach has already been proven in many studies (Ahmed-Kristensen et al., 2014; Keshwani et al., 2017) and won't be the tackled of this article. Instead, we will focus on the methodological framework surrounding the use of biomimetics as a technical problem-solving approach, referred to as the technical-pull approach (ISO/TC266, 2015). Few argue against biomimetics, but its implementation and practice are still highly limited. Indeed, after the overwhelming awareness of its potential, industrials soon faced a major question: how to use biomimetics as a systematic innovative strategy? Using nature as a source of inspiration appears economically and technologically promising, if not extremely logical from a sustainable point of view (Gamage and Hyde, 2012; Helfman Cohen and Reich, 2016), but it involves great challenges. Three of them have been specifically pinned down by researchers (Kruiper et al., 2018):

- The most obvious one is the requirement for biological data to be used as source of inspiration. How can design teams find suitable biological data for each, or at least most, of their design projects?

- A second aspect is the selection of suitable biological models. Even if biological data are made available for design teams, how can they identify, among the incredible diversity of living beings, which organisms are relevant for a given design problem?

- Finally, the understanding of these data. Biological articles are based on vocabulary, concepts, reasoning, experimental procedures and general biological knowledge that are hardly accessible for engineers who don't have a background in biology. How to overcome the design teams' lack of biological knowledge?

Hitherto, engineering designers have been focusing on solving these issues by making biological data accessible for engineers through biomimetic tools and processes.

This article takes a different standpoint and tackles the above-mentioned issues through the methodological integration of profiles having a background in biology during the biomimetic process. Taking as a starting point that biologists should be part of biomimetic teams, our study deals with the following research question: How to integrate biologists within biomimetic teams in order to optimize the biomimetic process?

By following the Design Research Methodology (DRM) (Chakrabarti and Blessing, 2009), we investigated the key elements that have to be considered in order to propose an answer to our research question in the form of a transdisciplinary biomimetic process. This article will then conclude on the perspectives and on-going testing phases of the proposed process.

\section{STATE OF THE ART}

Through the presentation of the main methodological approaches in biomimetics, this state of the art underlines the current limitation of biomimetics and presents the need for integration of a recognized, yet neglected, piece of the biomimetics' methodological puzzle: the biologists.

\subsection{Current biomimetic technology-pull processes, a theoretical approach}

For the past decades, a great number of methods have been designed to help implement a technologypull approach. The first approach is to formalize the biomimetic process through the observation of the practice of biomimetics and the identification of the main constraints and cognitive steps followed by the participants. This methods are said to be analytical (Wynn and Clarkson, 2005) : The procedural model of doing bionics (Lindemann and Gramann, 2004), Biomimetic design methodology (Lenau, 2009), Problem-driven analogical process (Goel et al., 2014), etc. These processes describe the practice of biomimetics at an overall level which makes its implementation difficult in an industrial context. At the level of the steps it isn't clear how the challenges identified in the introduction are dealt with. In addition to these approaches, some procedural processes have been designed and described with great details. Based on semantic formalizations, like SAPPhIRE (Chakrabarti, 2009), Biomimicry Taxonomy (Baumeister, 2012) or FBS (Vattam et al., 2011), etc., these processes are organized around databases, 
IDEA-Inspire (Chakrabarti et al., 2005), AskNature (Biomimicry Institute, 2002), DANE (Vattam et al., 2011), etc. They thus rely on semantic modelization and databases to answer the previously identified challenges. Because of the specific semantic modelization related to each process, these approaches can be hard to use without training. Moreover, their efficiency highly depends on the quality of their respective database. This strong reliance leads to a situation where, in practice, the most used process should progressively be the one with the most efficient tool, without considering the formalisation relevance or, more generally, the methodological viewpoint. Recent development in artificial intelligence have led research teams of the Toronto University to work on a computational process based on semantic analyses of all the articles available on biology database from requests formalized in a natural language (Cheong et al., 2011; Ke et al., 2010). These promising studies are still under development and so don't represent a currently available solution.

Finally, the last kind of methodological solutions to the challenges identified in the introduction are abstract approaches. These processes are based on the abstraction of biological knowledge into generic strategies for solving problems, avoiding the issues related to the use of raw biological data. The most advance abstract process has been formalized by Vincent and is inspired from TRIZ (Vincent, 2016). It focuses on trade-offs (Vincent, 2017) and more specifically on how living beings solve trade-offs. Because of the very high level of abstraction of such approach, the process doesn't need actual biological data as it is based on a previous determination of all the trade-offs and natural generic strategies associated (Kruiper et al., 2018). To have access to those strategies, a tool is currently under development in the form of an ontology (Vincent and Cavallucci, 2018). The potential limitations of this strategy can be compared to the ones of TRIZ. Concepts at such a high level of abstraction are often hard to manipulate and even if it may become an extremely powerful approach, it also may require an intensive training to be used efficiently. According to Fayemi all these processes can be described with the same eight main steps. As a result, he proposed a unified technology pull biomimetic process (Fayemi et al., 2017) that will be considered in this article as our reference process (Figure 1).

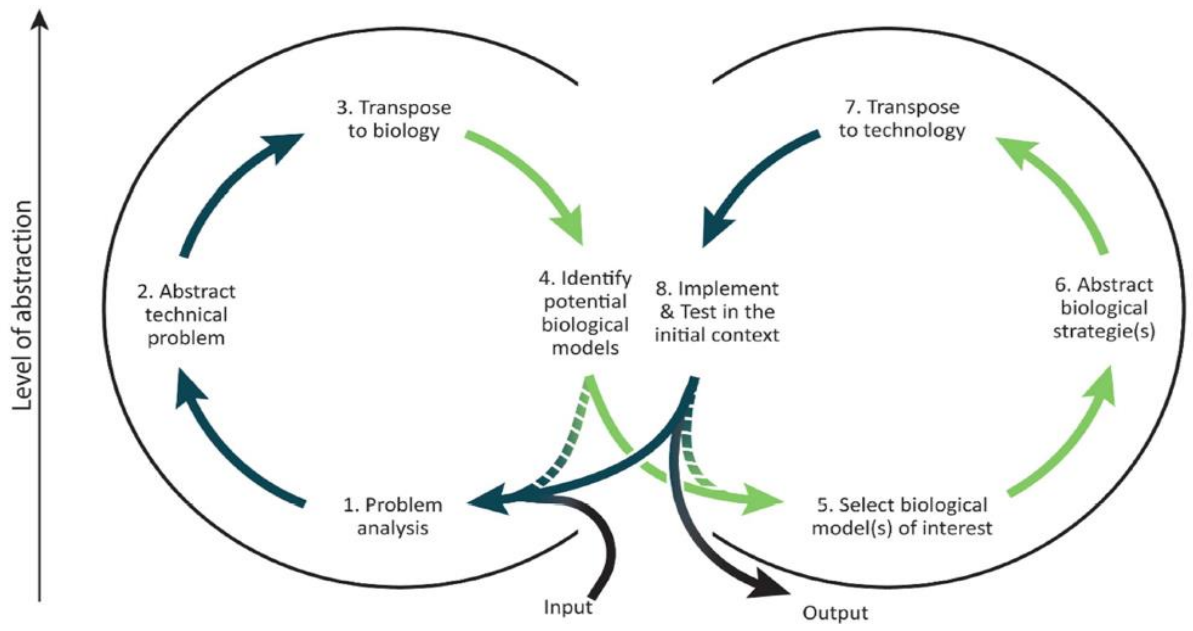

Figure 1. The unified technology-pull biomimetic process (figure from Fayemi et al., 2017)

As we've seen, engineering design on biomimetics isn't new, but so far it has failed to achieve its final objective as the use of biomimetics is still very limited in the industrial world. Lots of the studies above mentioned are still under-development and it is then too soon to evaluate their efficiency, but they all have in common to focus on tools and modelization to solve the challenges of biomimetics.

\subsection{Current biomimetic tools, the unrealistic expectations}

To perform the different steps of the above-mentioned processes, a large number of tools have been designed. Wanieck et al. (Wanieck et al., 2017) performed a classification and analysis of more than 40 tools related to the practice of biomimetics. As often in engineering design, the increasing number of tools leads the user into an unclear path as it becomes more complicated to choose which tool to use, and in which conditions (Lahonde, 2010). A deep analysis of the tools used in biomimetic design have underline three main origins (Fayemi, 2016) : engineering - like 5-Whys (Ohno, 1978), Technical contradictions (Altshuller, 1988), etc. - biology - like 16 Patterns of Nature (Hoagland and Dodson, 1995), Functional 
modelization (Tinsley et al., 2007), etc. - or have been conceived for biomimetic purposes - like the Biomimicry Taxonomy (Baumeister, 2012), BIOTRIZ (Vincent et al., 2006), etc.

These tools aim at helping designers to overcome the challenges previously stated, but the expectations towards them appear unrealistic. For example, the requirement for biological data is mainly solved through databases which are extended manually, with information that have to be scientifically verified and supported by scientific articles before being translated from biology to a given semantic formalization (example with AskNature : Deldin and Schuknecht, 2014). It appears clear that such type of tools is of great interest but faces a considerable difficulty which is the trade-off between the quantity and the quality of the referenced data. The biggest biomimetic database ever designed - AskNature - encompasses 1897 elements (1 696 biological strategies and 201 inspired ideas) (Biomimicry Institue, 2018) and even if this number is substantial, it is far from being sufficient to be used as the source of biological data by design team at a global scale. As previously explained, Artificial Intelligence may be the future answer to the problem of biological data's accessibility, but sorting algorithms are for the present time under development and, as a result, don't represent an actual fitting solution (Cheong and Shu, 2012; Vandevenne et al., 2015). The limitation of biomimetic tools can be observed for each of the challenges of biomimetics. Another example is the understanding of biological data which isn't linked with a specific step but is transversal in all steps related to biology. Tools that enable the understanding of biological data are mainly thesaurus, ontologies or algorithms leading to their formalization into models (Wanieck et al., 2017). These tools give some strong intakes in terms of abstraction and analogical reasoning, but they are severely time consuming if performed by users who don't have any background in biology. Moreover, they tend to modelized biological systems separated from their extended context which may imply the loss of crucial information. Besides, the risk of misinterpretation or misunderstanding is high (Helms et al., 2009; Vattam et al., 2007) and can lead to a technical dead end, which would cost time, money and potentially the appeal of the industrials for biomimetics. Overall, it is unlikely that these tools will solve by themselves the challenge of understanding biological data.

These observations bring us to the following conclusion: most of the biomimetic tools are highly relevant but aren't sufficient to overcome the challenges of biomimetics. Tools constitute the bones of the biomimetic skeleton that is the biomimetic process, but some pieces of the puzzle are still missing. The next section focuses on the composition of the biomimetic design team as one of the main levers of innovation, and more especially on considering biologists' expertise and knowledge during the biomimetic process.

\subsection{A pluridisciplinary team, a highly recognized yet ignored starting point}

Pluridisciplinarity in design isn't a new thing. Because of their intrinsic link with engineering, physics and mathematics have always been related to the design practice. One could even argue that engineers constitute a type of mathematicians or physicists. Throughout the history of design, several profiles have been added to the typical design teams (Cross, 1993). Thus, with the rising awareness of the consumers' needs and expectations profiles from human and social sciences - like ergonomists (Aoussat et al., 2000) - have been included in design teams and processes. Biology emerges as the last 'hard science' remaining out of the design scope, explaining why this association appears so promising. However, even if the potentialities of biology in design are well established, biologists remain mainly excluded of the design practice. Nonetheless, several articles have been published with the objective of exposing the assets that are biologists in biomimetics (Graeff et al., 2018a; SnellRood, 2016), their inputs during creativity steps (Schöfer, 2015), innovative problem-solving approach (Schöfer et al., 2018), etc. One of our initial reflection on the articles dealing with biomimetic process or tools is that the required profiles of the practitioners remain most of the time unspecified. Readers (mostly researchers in engineering or engineering design), logically assume that these processes are expected to be followed by "typical design teams" (mechanical engineers, designers, ergonomist, etc.) but the question "who is the target of those methodological innovations?" isn't clearly answered. Some articles presenting the design of databases, AskNature for example, explain that biological data available through such tools are translated by experts in biology in order to ensure the quality of the information and make databases usable for engineers (Deldin and Schuknecht, 2014). On processes, some articles underline without any further details, that biologists are assets to be included during the process (Badarnah and Kadri, 2015; Fayemi, 2016; Vattam et al., 2008). However, no information is given on the manner they should be integrated, for what exact role(s), or at which step(s), etc. 
Additionally, biologists form a highly varied community with very different expertise, thus, which "biologists" are we talking about in biomimetics? The lack of information in the literature towards biologists' characteristics in the context of biomimetics is one of the reasons why they aren't currently included in the biomimetic process. Companies that want to do biomimetics with biologists actually don't know which biologist to include and how to include them.

It is acknowledged that biologists are a profile of interest in biomimetics, but they aren't actually integrated and if they are, they remain restricted to a specific biological task like the translation of biological data. This approach considers biologists either as outsiders or as tools, it doesn't allow them to join the teams, play an active part and bring innovative thinking during the biomimetic design process. This quick state of the art focused on the methodological framework surrounding the practice of biomimetics led us to consider biologists as the missing pieces of the biomimetic design teams and processes.

\section{RESEARCH QUESTION AND HYPOTHESIS}

The above-described state of the art brings us to the following research question: How to integrate biologists within biomimetic teams in order to optimize the biomimetic process? Our hypothesis will be presented in the form of a transdisciplinary design process describing, at each step, biologist's role within the biomimetic design team. As it is extremely hard to choose which biologists should be integrated, we will instead determine what are the needs, and so what are the knowledge or know-how to expect from a biologist in biomimetics. Besides, to include new profiles, space is required. We need to determine which part of the biomimetic design process, currently missing or performed by engineers, should be assigned to biologists or conducted by both profiles.

Following the DRM (Chakrabarti and Blessing, 2009), we will firstly present our finding in the descriptive phase before proposing, in the prescriptive phase, a transdisciplinary biomimetic process adapted from the unified problem-driven biomimetic process designed by Fayemi (Fayemi et al., 2017).

\section{DESCRIPTIVE PHASE: IDENTIFICATION OF THE KEY ELEMENTS}

In a previous article, we've described the results of a survey completed by 195 people from both the biology and the engineering world (Graeff et al., 2018b). The main limitation of this study was the relatively low level of knowledge of the respondents on methodological aspects of biomimetics (referred to as "Neophytes" in this article). In order to deal with this limitation, we've asked six biomimetics' experts (referred to as "Experts" in this article) for their opinion through a similar survey. The combine results are presented as bullet points describing key elements of this descriptive phase.

First, our work appears relevant since the results call for:

- A methodological work to guide biologists in their practice of biomimetics (Neophytes and Experts) and built a defined position for biologists in design teams (Experts).

Key elements at the overall scale:

- At the scale of the process, neophytes from both engineering and biology consider that biologists should be integrated. However, part of the sample asks for an integration at each step of the process where the other part support an integration only during biology-related steps. This dichotomous approach is also found in experts' response.

- Neophytes from engineering identify the potentialities of biologists' integration during postabstraction creativity work.

- Both neophytes and experts underlined the need for more communication and popularization on both sides of the scientific field.

- Neophytes' results show that the sustainability of a project is a strong motivation for a biologist to join a biomimetic team and experts support the idea that biomimetics is often used as a sustainable innovation strategy.

Key elements on the biologist profile:

- Both neophytes and experts think that both engineers and biologists should have basic knowledge on each other's scientific field but not necessarily on tools or technical parts.

- Both neophytes and experts consider that integrated biologists need a large but basic knowledge on as much fields of biology as possible (referred to as "horizontal knowledge" in this article) as well as a deep knowledge on precise organisms or mechanisms (referred to as "vertical knowledge" in this article). 
As a conclusion to the survey, we've asked experts a very broad question: "In your expert opinion, why is biomimetics still a very fragile and so confined innovation strategy in the modern industry?". Three main aspects emerged:

- The lack of financial investments, "support and acceptance for this kind of transdisciplinary processes". Which can be explained by the absence of proof "that it works for industries".

- The lack of communication between the different scientific fields and integration of profiles with background in natural sciences.

- The lack of academic training.

From all these results, we made informed choices in order to propose a methodological solution to the identified needs. After the presentation of the results obtained during the descriptive phase, the next section presents the selected axes of research and our methodological optimizations and innovations.

\section{PRESCRIPTIVE PHASE: PROPOSITION OF A TRANSDISCIPLINARY BIOMIMETIC PROCESS}

We've seen in the last section that numerous aspects have to be considered to build a suitable process allowing the integration of biologists in biomimetic teams. In order to answer the need in biological knowledge previously identified, we made the choice to consider two generic profiles to be integrated, a horizontal biologist (HB) and a vertical one (VB). Where VBs can be easily associated with researchers (experts in their field), HBs remain hard to define. They should firstly bring large biological knowledge and way of reasoning. Secondly, they will have to be trained in order to learn basic knowledge in design and biomimetic processes. Last, as they act as bridges between the biomimetic design teams and researchers, they must have strong communication skills and must be able to translate crucial information both ways. This profile is still ill-defined as it actually doesn't exist. Currently, only a few self-made experts fulfil this function, mostly as specialized consultant thanks to their experience in the field. Profiles which currently appear to be the most appropriated would be naturalists or biologists with specialisation in engineering. This first observation backs up experts' opinion on the absolute necessity for specific training programs for biologists.

Since this HB will be specialized in biology, biomimetics, and transdisciplinary work, we also suggest fully integrating the $\mathrm{HB}$, within biomimetic teams, as a permanent member. For cost purposes, this integration can occur at the scale of the laboratory or the R\&D department, but as the need for communication and popularization has been highly underlined in the descriptive phase, it appears necessary to create long lasting interdisciplinary teams who are used to work together and to communicate as a group. As a fully integrated member of biomimetic design teams, HBs will be included at each step of the biomimetic process, with variable levels of magnitude and variable roles depending on each step. On the contrary, VBs will only be consulted on a specific step, the abstraction of biological strategies, when the organisms of interest are well identified and when a deeper knowledge is required to abstract biological strategies at their core (Figure 2). This two-speed strategy aims at solving the need for both large and precise biological knowledge made during the descriptive phase. As we can see on the Figure 2, we don't prescribe an even integration for each step of the process. We are fully aware of the cost in terms of time and resources for such processes and as a result we included the different profiles only when truly relevant.

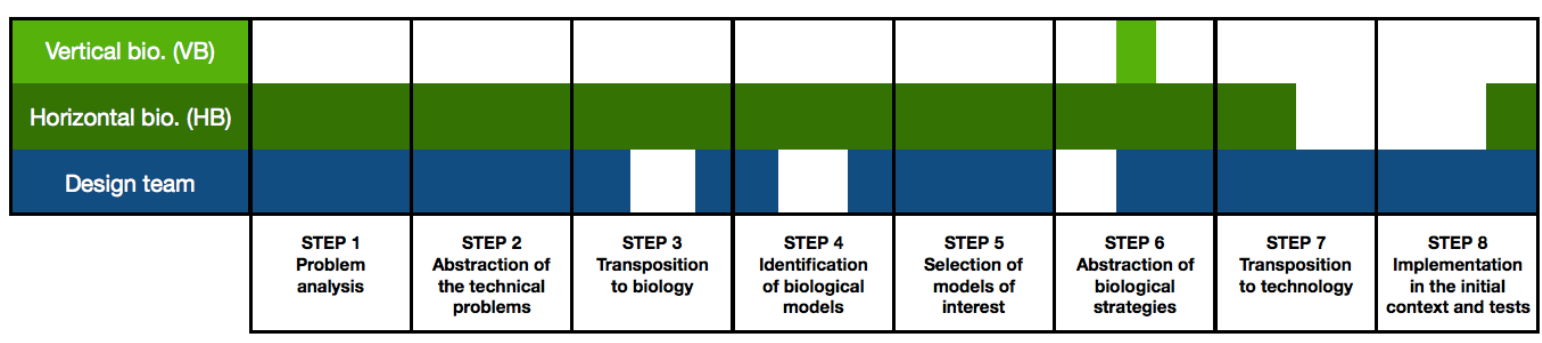

Figure 2. Repartition of biomimetic design team's members during the biomimetic process

From this starting point, we optimized the unified problem-driven biomimetic process proposed by Fayemi (Fayemi et al., 2017). As explained during the descriptive phase, the lack of proof for such process effectiveness, which can be quickly related to the concept of risk, is one of the obstacles preventing biomimetics implementation. In order to deal with this issue, we incorporated three "go no 
go" steps, well recognized concepts in product design, allowing short retroactive loops or in the worst case an early termination of the project, limiting the risks tied to this innovative strategy (Figure 3). Furthermore, we decided to differ from the visual aspect of the final version of the problem-driven biomimetic process representation proposed by Fayemi (Fayemi et al., 2017). Indeed, the former representation was shaped as an infinity symbol due to potential overall loops induced by issues or potentialities discovered during the 8th step. Such a shape is instinctively scary from an industrial perspective as it brings an uncertainty regarding the process' length, and so the required resources.

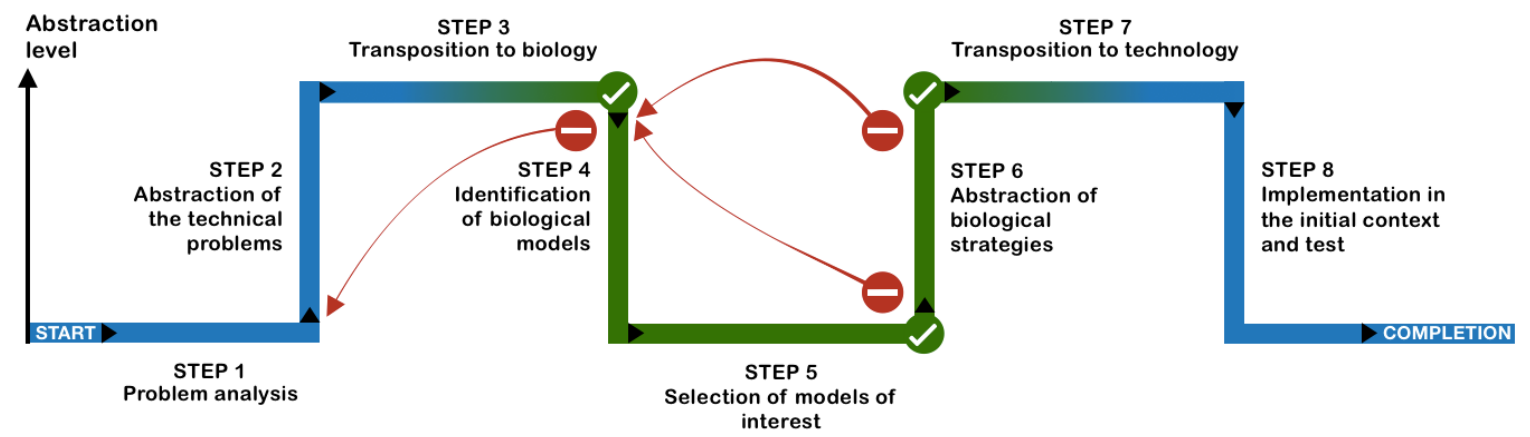

Figure 3. Optimized unified problem-driven biomimetic process adapted from Fayemi 2017

In addition to these modifications, this section also presents the different roles of the HB throughout the process. During the first two steps, that are centred on engineering aspects, the HB will have two active roles and one passive one. First, he acts as the "naïve member" of the team. As he doesn't have a deep expertise in technical issues, he will question other members of the team, forcing them to go deeper into detail, to communicate and to propose a well-define problem. Secondly, he brings variability during these steps by reasoning with a different approach, taking into consideration new parameters and potentially ensures the sustainability aspect (depending on the project), etc. Finally, its main and passive role during these first two steps will be to assimilate as much information as possible to prepare the third step.

To start the third step, the HB presents his understanding of the outputs obtained during the steps $1 \& 2$ to the rest of the team. When the whole team agrees on the problem and technical aspects, the $\mathrm{HB}$ is charged to transpose the technical problems into biological ones. The third step ends with the HB presenting to the rest of the team his transposition to the biology. When the whole team agrees on the biological problems that have to be studied, the first "Go/No go" is validated and the process goes on. If the team disagrees, a retroactive loop can occur in order to understand where the incoherence come from and to solve it before entering the rest of the process. This first " $\mathrm{Go} / \mathrm{No}$ go" milestone is crucial since this part of the process lasts for a relatively short period of time but defines the rest of the project.

The fourth step starts with a brainstorming with the whole team. The idea is to collect ideas of biological solutions from each member. Everyone has a small biological knowledge, or hobbies related one way or another to biology, or have read about biology somewhere. This brainstorming has multiple aims. Firstly, to include non-biologists in biology-centred steps. Innovation comes from the diversity of ideas, perspectives and interests, this step is a way to stimulate one another. Secondly, it allows the team's members to empty their head and to disregard any fixation points they might already have. The main part of the fourth step will then be performed by HB through their knowledge, knowhow and specialized biomimetic tools such as databases. At the end of the fourth step, the team gathers, and the identified biological strategies are presented.

The fifth step is the first convergent step of the process. Based on economic, biological, technological, and any specifications previously established, the whole team has to select which biological organisms will be use for the project. The information gathered during the fourth step have to be rich enough to enable this selection. If the selection is feasible, the second "Go/No go" milestone is validated and the process goes on. If it isn't, more information or different biological models might be required, and the team will go back on step 4.

During the sixth step of the process, the selected organisms will be extensively studied. Firstly, through an in-depth analysis of the relevant scientific literature by the HB. Then, if necessary, the analysis goes on through the external input of VB specialized on the selected organisms. Once the underlying biological properties are understood by the HB, the team gathers and work on the abstraction of the biological strategies into models accessible for every members of the team while at 
the same time displaying the key elements of the biological strategies. If needed, the abstracted models thus obtained can be validated by a presentation to the VB. This third "Go/No go" milestone then ensure the validity of the biological model and the agreement of the relevant stakeholders to begin the transposition to technology, leading to the final part of the process.

These final steps (7-8) are mainly handled by the non-biologist team members. However, as underlined in the descriptive phase, diversity is a powerful asset during creativity steps and as a result, we suggest including HB during creativity steps and for the choice of the final design concept. The rest of the technical development is left to the engineers of the team. Finally, HB can be involved during the testing phase of the eighth step, to evaluate the sustainability of the final product for example.

The prescriptive phase of our study represents a hypothesis answering the research question of this article on the way to integrate biologists. It describes both the interaction of the HB with the other team members and its specific role during the biomimetic design process. The addition of "Go/No go" steps also allows a step by step validation of the process, reducing the risks for the industrials. This process is still under development and is simultaneously tested to obtain feedbacks for optimization.

\section{DISCUSSION AND PERSPECTIVES}

The process described in the last section is, to the best of the authors knowledge, the first biomimetic process truly including biologists and considering them as a part of the biomimetic design teams. It proposes different roles for both $\mathrm{HB}$ and VB during the biomimetic design process and legitimizes their integration as a response to the optimization levers identified during the descriptive phase of our study. In addition to the necessary tests on the impact of such optimized process in an actual industrial context, one of the remaining questions will focus on the definition of the profile we referred to as horizontal biologists in this article. Are they necessarily coming from a biological background, or should we instead consider these profiles as actors having the required "blocks" of knowledge, knowhow and expertise, but who can have either a background in biology, engineering or even design ? This overall version of our transdisciplinary biomimetic process is currently detailed, tested and optimized through two different projects. An on-going 10-month student project, combining the expertise of both students in biology and in engineering (until July 2019), and a one-year industrial project (until April 2020). These two projects will allow us to complete the DRM methodology through a post-implementation descriptive phase.

\section{CONCLUSION}

After a quick state of the art, we notice that even if recognized as potential valuable assets, and sometimes even used in practice, biologists are neither currently included in biomimetic team nor in the biomimetic methodological framework. This observation leads us to consider the research question tackled in this article: How to integrate biologists within biomimetic teams in order to optimize the biomimetic process? Through an analysis of the state of the art and of feedbacks of students, professionals and biomimetics experts we identified a set of parameters to consider during the design of a biomimetic design process including biologists. This article then proposes a first version of a transdisciplinary biomimetic design process based on the consideration of two different type of biologists: horizontal (HB) and vertical (VB). By methodologically giving biologists spaces to fulfil their role as members of biomimetic design teams, we both answer the question of the integration within the team and during the process. We believe that this process is precise enough to allow a necessary transdisciplinary shift while remaining large enough to be applied in all sorts of design projects. We will pursue our work by evaluating this process through both a student and an industrial project. This realistic experimental context will drive us to optimize our suggestions and determine which are the most pertinent tools to be used to allow all members to carry out their missions. The aim of this process is to make available a true methodological framework to support industrials who want to implement biomimetics and create actual positions for biologists within biomimetic design teams or laboratories. Insofar as the horizontal biologists described in our work isn't an already existing profile, this first version of our biomimetic process will hopefully help define transdisciplinary horizontal biologists in biomimetics and so build training programs for young biologists wanting to join the biomimetic adventure. 


\section{ACKNOWLEDGMENT}

Thanks to all the students and professionals that have given time and energy for this project.

\section{REFERENCE}

Ahmed-Kristensen, S., Christensen, B.T. and Lenau, T. (2014), "Naturally original: Stimulating creative design through biological analogies and Random images”, International Design Conference, Dubrovnik, pp. 427436.

Altshuller, G.S. (1988), Creativity as an Exact Science: The Theory of the Solution of Inventive Problems, Journal of Development Economics, 1 edition., Vol. 91, CRC Press, New York.

Aoussat, A., Christofol, H. and Le Coq, M. (2000), “The new product design - A transverse approach", Journal of Engineering Design, Vol. 11 No. 4, pp. 399-417.

Badarnah, L. and Kadri, U. (2015), "A methodology for the generation of biomimetic design concepts", Architectural Science Review, Taylor \& Francis, Vol. 58 No. 2, pp. 120-133.

Baumeister, D. (2012), Biomimicry Resource Handbook: A seed bank of knowledge and best practices, Biomimicry Resource Handbook, CreateSpace Independent Publishing Platform, Missoula, available at: https://doi.org/10.1017/CBO9781107415324.004.

Biomimicry Institue. (2018), “AskNature - Innovation Inspired by Nature”, available at: https://asknature.org/ (accessed 23 November 2018).

Biomimicry Institute. (2002), “AskNature - Innovation Inspired by Nature”, AskNature.

Chakrabarti, A. (2009), "Sapphire - an Approach To Analysis and Synthesis", Iced'09, No. August, pp. 417428.

Chakrabarti, A. and Blessing, L.T.M. (2009), “DRM: A Design Reseach Methodology”, DRM, a Design Research Methodology, Springer London, London, pp. 13-42.

Chakrabarti, A., Sarkar, P., Leelavathamma, B. and Nataraju, B.S. (2005), "A functional representation for aiding biomimetic and artificial inspiration of new ideas", Ai Edam, Vol. 19 No. 02, pp. 113-132.

Cheong, H., Chiu, I., Shu, L.H., Stone, R.B. and McAdams, D.A. (2011), "Biologically Meaningful Keywords for Functional Terms of the Functional Basis", Journal of Mechanical Design, Vol. 133 No. 2, p. 021007.

Cheong, H. and Shu, L.H. (2012), "Automatic extraction of causally related functions from natural-language text for biomimetic design", available at: http://shulab.mie.utoronto.ca/wpcontent/uploads/pubs/Cheong_etal_DTM_12.pdf (accessed 23 March 2018).

Cross, N. (1993), “A History of Design Methodology”, Design Methodology and Relationships with Science, Springer Netherlands, Dordrecht, pp. 15-27.

Deldin, J.M. and Schuknecht, M. (2014), "The AskNature Database: Enabling Solutions in Biomimetic Design", Biologically Inspired Design, Springer, London, pp. 17-28.

Fayemi, P.E. (2016), Innovation through Bio-Inspired Design : Suggestion of a Structuring Model for Biomimetic Process and Methods, ENSAM - Paris.

Fayemi, P.E., Wanieck, K., Zollfrank, C., Maranzana, N. and Aoussat, A. (2017), "Biomimetics: Process, tools and practice", Bioinspiration and Biomimetics, Vol. 12 No. 1, p. 11002.

Gamage, A. and Hyde, R. (2012), “A model based on Biomimicry to enhance ecologically sustainable design”, Architectural Science Review, Taylor \& Francis, Vol. 55 No. 3, pp. 224-235.

Goel, A.K., Vattam, S., Wiltgen, B. and Helms, M. (2014), "Information-Processing Theories of Biologically Inspired Design", Biologically Inspired Design, Springer, London, pp. 127-152.

Graeff, E., Maranzana, N. and Aoussat, A. (2018a), "Role of biologists in biomimetic design processes : preliminary results", International Design Conference, Dubrovnik, pp. 1149-1160.

Graeff, E., Maranzana, N. and Aoussat, A. (2018b), "Conception biomimétique : quels acteurs pour quelles attentes?", Confere Conference.

Helfman Cohen, Y. and Reich, Y. (2016), Biomimetic Design Method for Innovation and Sustainability, available at:https://doi.org/10.1007/978-3-319-33997-9.

Helms, M., Vattam, S. and Goel, A.K. (2009), "Biologically inspired design: process and products", Design Studies, Vol. 30 No. 5, pp. 606-622.

Hoagland, M. and Dodson, D. (1995), The Way Life Works, 1st ed., Crown, New York.

ISO/TC266. (2015), "Biomimétique -Terminologie, concepts et méthodologie", available at: https://www.iso.org/fr/committee/652577/x/catalogue/.

Ke, J., Wallace, J.S., Chiu, I. and Shu, L.H. (2010), "Supporting Biomimetic Design by Embedding Metadata in Natural-Language Corpora", Proceedings of the ASME 2010 International Design Engineering Technical Conferences \& Computers and Information in Engineering Conference IDETC/CIE 2010, pp. 1-8.

Keshwani, S., Lenau, T.A., Ahmed-Kristensen, S. and Chakrabarti, A. (2017), "Comparing novelty of designs from biological-inspiration with those from brainstorming”, Journal of Engineering Design, Vol. 28 No. 10-12, pp. 654-680. 
Kruiper, R., Vincent, J., Abraham, E., Soar, R., Konstas, I., Chen-Burger, J., Desmulliez, M. et al. (2018), "Towards a Design Process for Computer-Aided Biomimetics", Biomimetics, Multidisciplinary Digital Publishing Institute, Vol. 3 No. 3, p. 14.

Lahonde, N. (2010), Design Process Improvement : Proposal of a Model for Design Methods Selection to Support the Decision, ENSAM - Paris.

Lenau, T. (2009), "Biomimetics as a design methodology - Possibilities and challenges", International Conference on Engineering Design, pp. 121-132.

Lindemann, U. and Gramann, J. (2004), "Engineering design using biological principles", International Design Conference, Dubrovnik, pp. 355-360.

Ohno, T. (1978), Toyota Production System: Beyond Large-Scale Production, Productivity Press, 1 edition., Vol. 1, Productivity Press, Cambridge, Mass, available at:https://doi.org/10.1108/eb054703.

Schöfer, M. (2015), Processes and Methods for Interdisciplinary Problem Solving and Technology Integration in Knowledge-Intensive Domains, ENSAM - Paris.

Schöfer, M., Maranzana, N., Aoussat, A., Bersano, G. and Buisine, S. (2018), "Distinct and combined effects of disciplinary composition and methodological support on problem solving in groups", Creativity and Innovation Management, Vol. 27 No. 1, pp. 102-115.

Snell-Rood, E. (2016), "Interdisciplinarity: Bring biologists into biomimetics", Nature, Vol. 529 No. 7586, pp. 277-278.

Tinsley, A., Midha, P., Nagel, R. and McAdams, D. (2007), "Exploring the Use of Functional Models As a Foundation for Biomimetic Conceptual Design", ASME 2007 International Design Engineering Technical Conferences and Computers and Information in Engineering Conference, pp. 1-15.

Vandevenne, D., Verhaegen, P.A., Dewulf, S. and Duflou, J.R. (2015), "A scalable approach for ideation in biologically inspired design”, Artificial Intelligence for Engineering Design, Analysis and Manufacturing, Vol. 29 No. 01, pp. 19-31.

Vattam, S., Helms, M. and Goel, A.K. (2007), Biologically-Inspired Innovation in Engineering Design: A Cognitive Study, Technical Report, Graphics, Visualization and Usability Center, Georgia Institute of Technology, available at: https://smartech.gatech.edu/handle/1853/14346 (accessed 22 February 2018).

Vattam, S., Helms, M. and Goel, A.K. (2008), "Compound Analogical Design: Interaction between Problem Decomposition and Analogical Transfer in Biologically Inspired Design”, Design Computing and Cognition, Springer Netherlands, Dordrecht, pp. 377-396.

Vattam, S., Wiltgen, B., Helms, M., Goel, A.K. and Yen, J. (2011), "DANE: Fostering Creativity in and through Biologically Inspired Design”, Design Creativity 2010, Springer London, London, pp. 115-122.

Vincent, J. (2016), "TRIZ as a Primary Tool for Biomimetics", Research and Practice on the Theory of Inventive Problem Solving (TRIZ), Springer International Publishing, Cham, pp. 225-235.

Vincent, J. and Cavallucci, D. (2018), “Development of an Ontology of Biomimetics Based on Altshuller's Matrix", Springer, Cham, pp. 14-25.

Vincent, J.F.V. (2017), "The trade-off: a central concept for biomimetics", Bioinspired, Biomimetic and Nanobiomaterials, Thomas Telford Ltd, Vol. 6 No. 2, pp. 67-76.

Vincent, J.F.V., Bogatyreva, O.A., Bogatyrev, N.R., Bowyer, A. and Pahl, A.K. (2006), "Biomimetics: its practice and theory", Journal of The Royal Society Interface, Vol. 3 No. 9, pp. 471-482.

Wanieck, K., Fayemi, P.E., Maranzana, N., Zollfrank, C. and Jacobs, S. (2017), "Biomimetics and its tools", Bioinspired, Biomimetic and Nanobiomaterials, Vol. 6 No. 2, pp. 53-66.

Wynn and Clarkson. (2005), "Chapter 1 - Models of designing", Design Process Improvement: A Review of Current Practice, pp. 34-59. 